\title{
Model Pengenalan Benda Bersejarah Indonesia Bagi Wisatawan Berbasis Augmented Reality
}

\author{
Erizal $^{1}$, Putra Wanda ${ }^{2}$ \\ ${ }^{1}$ Program Studi Sistem Informasi, ${ }^{2}$ Program Studi Teknik Informatika \\ Universitas Respati Indonesia

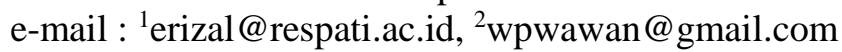

\begin{abstract}
This research will build a model of learning through the introduction of types and forms of historical objects in Indonesia based on $3 D$ with the concept of augmented reality. If applied to the real world, this application will make it easier for tourists to learn about the types of historic objects of Indonesia through interactive images that are connected with internet-based applications.
\end{abstract}

Keyword : Augmented Reality, Information System

\begin{abstract}
Abstrak
Penelitian ini akan membangun model pembelajaran melalui pengenalan jenis dan bentuk benda bersejarah di Indonesia berbasis 3D dengan konsep augmented reality. Jika diterapkan pada dunia nyata, aplikasi ini akan memudahkan para wisatawan untuk belajar mengenai jenis-jenis benda bersejarah Indonesia melalui gambar interaktif yang terkoneksi dengan aplikasi berbasis jaringan internet.
\end{abstract}

Kata kunci : Augmented Reality, Sistem Informasi

\section{PENDAHULUAN}

Perkembangan aplikasi teknologi informasi khususnya dalam bidang dan pesatnya perkembangan perangkat mobile saat ini bisa digunakan untuk mengenalkan berbagai hal yang berhubungan dengan budaya Indonesia termasuk benda bersejarah. Augmented Reality merupakan salah satu bagian computer vision yang banyak digunakan untuk deteksi objek, data spasial hingga pelacakan perilaku sebuah objek tertentu, sehingga muncul sebuah istilah "Augment your Reality" [1].

Teknologi Computer Vision sangat bermanfaat jika diterapkan pada sebuah proses dokumentasi objek nyata maupun maya secara real time. Hal inilah yang menjadi salah satu faktor utama yang membuat banyak aplikasi memanfaatkan konsep di atas untuk menyelesaikan permasalahan deteksi, pengenalan objek seperti warisan budaya dan navigasi terhadap sebuah kondisi tertentu [2].

Oleh karena itu, penelitian ini dilakukan untuk membangun model pengenalan jenis dan bentuk benda bersejarah di Indonesia berbasis 3D yang bisa diakses secara mobile dan real time. Jika diterapkan pada dunia nyata, model ini akan sangat memudahkan seseorang untuk mengenal dan belajar mengenai jenis benda/objek bersejarah melalui gambar interaktif yang terkoneksi dengan aplikasi berbasis jaringan internet [3].

Berikut ini adalah contoh implementasi sistem berbasis augmented reality [4] : 


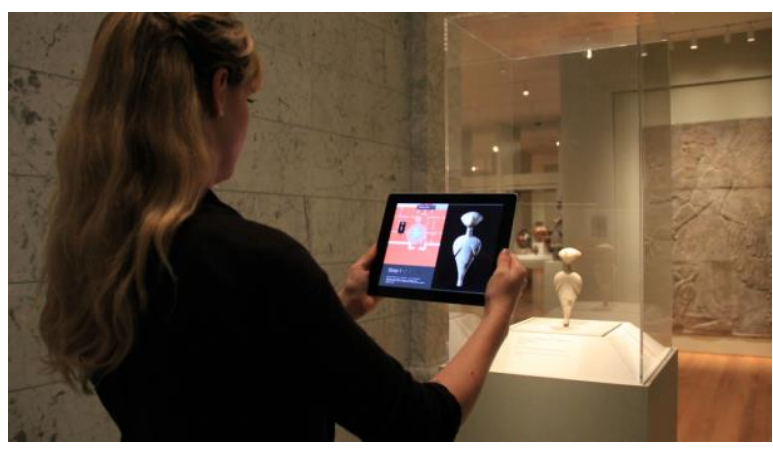

Gambar 1. Implementasi Augmented Reality

Penelitian ini bertujuan untuk membangun sebuah model pembelajaran yang dapat membantu dalam proses mengenali jenis benda bersejarah baik yang berbentuk gambar atau objek nyata melalui proses tracking 3D yang bersifat real time.

Hasil Penelitian yang diharapkan adalah sebagai berikut :

1. Membantu masyarakat khususnya wisatawan yang ingin mengenali dan belajar tentang bentuk dan jenis benda bersejarah beserta filosofinya.

2. Dapat dijadikan sebagai alat pembelajaran bagi siswa dalam proses pengajaran mata pelajaran seni rupa dan budaya.

3. Dapat memudahkan dalam mengenal kembali dan melestarikan warisan budaya yang sudah hampir hilang.

\section{METODE PENELITIAN}

\subsection{Metode Pengumpulan Data}

Adapun metode pengumpulan data yang digunakan yaitu :

\section{Metode Observasi}

Metode Observasi adalah suatu cara pengumpulan data dimana peneliti langsung dalam mengadakan pengamatan terhadap obyek yang akan diangkat sebagai sampel pada penelitian ini.

2. Metode Kearsipan

Metode kearsipan adalah suatu cara pengumpulan data dengan membaca dan mempelajari arsip-arsip yang berhubungan dengan masalah yang akan diteliti.

3. Metode Kepustakaan

Metode kepustakaan adalah suatu cara pengumpulan data dengan membaca dan mempelajari literatur-literatur yang berkaitan dengan permasalahan yang dihadapi.

\subsection{Metode Pengembangan Perangkat Lunak}

Metode Pengembangan perangkat lunak ini nantinya menggunakan metode Waterfall. Seperti pada gambar berikut ini : 


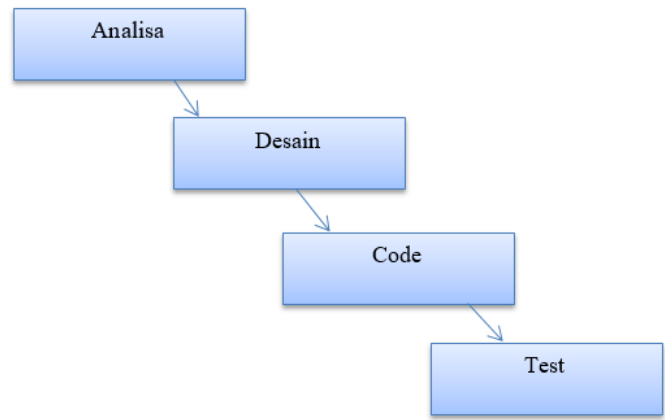

\section{Gambar 2. Metode Waterfall}

\section{HASIL DAN PEMBAHASAN}

Proses perancangan model aplikasi dengan menggunakan pengenalan objek. Konsep yang akan digunakan utuk membangun model pengenalan objek bersejarah Indonesia adalah dengan Teknologi Augmented Reality. Pada penelitian ini, metode yang akan digunakan untuk melakukan indetifikasi, deteksi objek, hingga penngenalan objek adalah dengan menggunakan metode Markerless Tracking.

Peneliti akan menggunakan metode markerless based Tracking yang diterapkan pada augmented reality. Dengan metode ini pengguna tidak perlu lagi menggunakan sebuah marker untuk menampilkan elemen-elemen digital, Metode ini sangat cocok diterapkan pada objek 3D karena dapat mengenali semua bentuk benda yang ada disekitar, seperti Keris, mobil, meja, televisi, dan lain-lain.

Penelitian dengan metode di atas digunakan untuk membangun sebuah model pengenalan benda berbasis Augmented Reality agar dapat memudahkan dalam penerapan di dunia nyata. Dengan metode pemodelan di atas, aplikasi nantinya dapat membantu dalam proses mengenali jenis benda bersejarah baik yang berbentuk gambar atau objek nyata melalui proses tracking 3D yang bersifat real time.

Berikut ini rancangan sistem augmented reality :

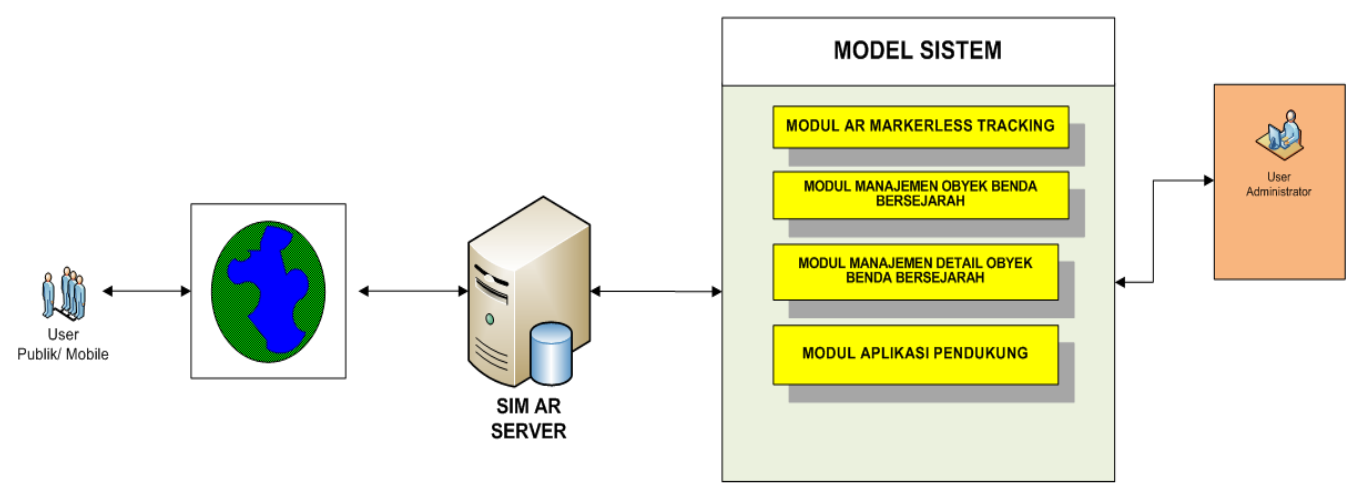

Gambar 3. Rancangan Sistem 


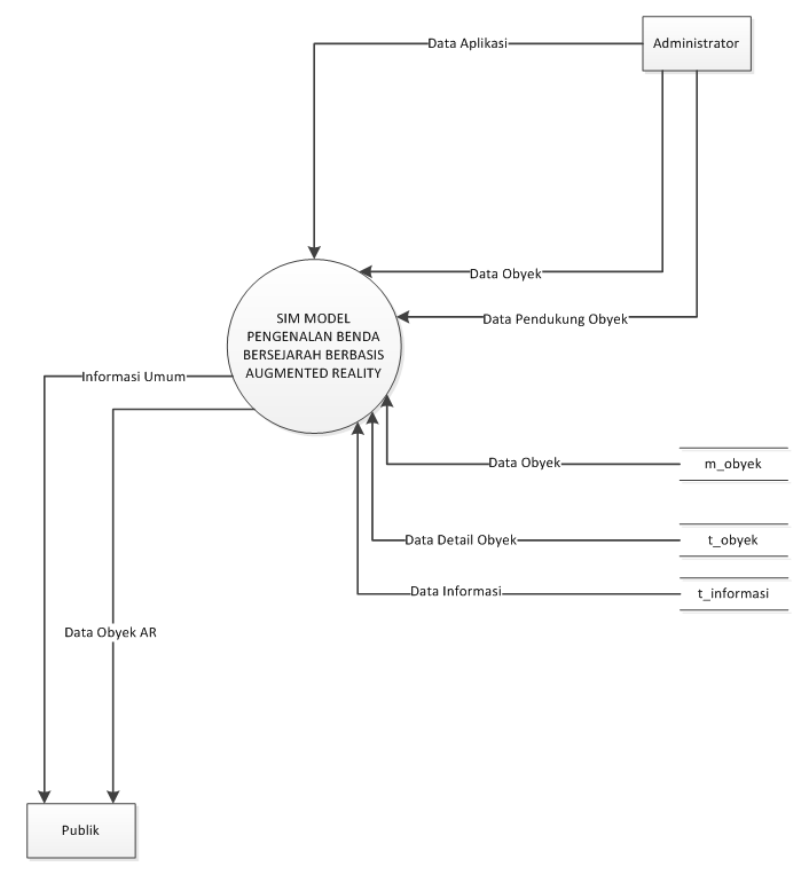

Gambar 4. Model Alur Data

Berikut ini hasil implementasi sistem :

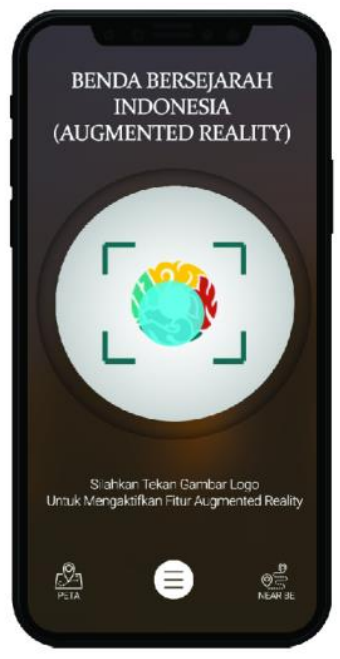

Gambar 5. Beranda

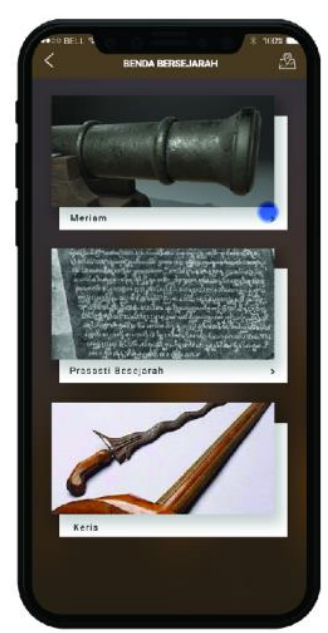

Gambar 6. Informasi 


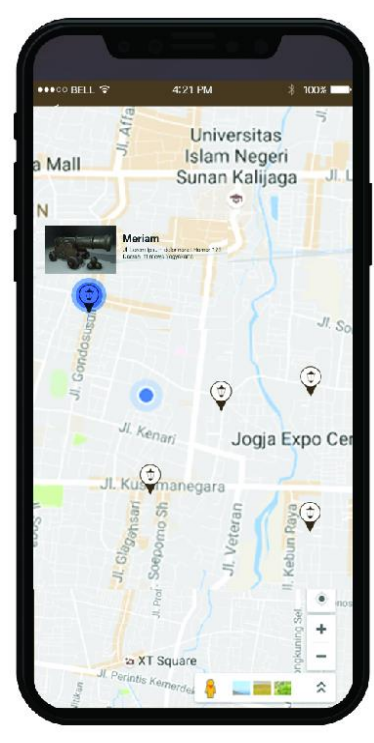

Gambar 7. Peta Lokasi

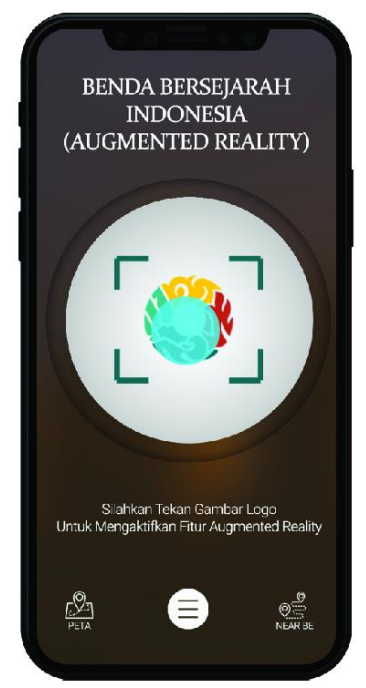

Gambar 8. Aktifasi AR

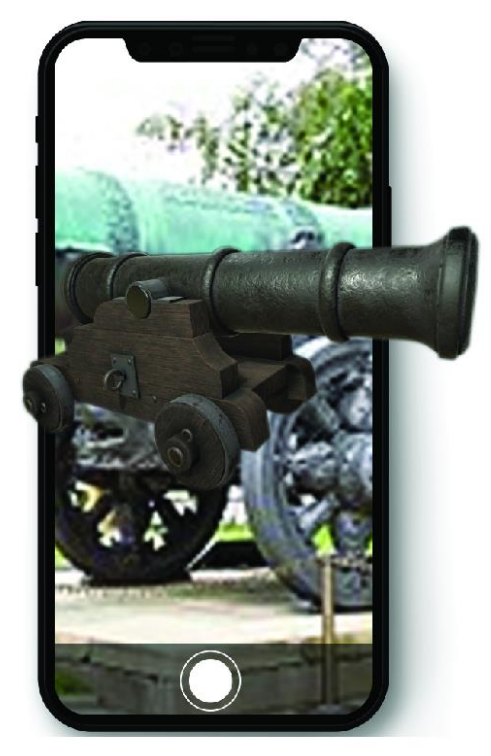

Gambar 9. Hasil Augmented Reality

\section{KESIMPULAN}

Dari hasil penelitan ini dapat diambil kesimpulan yaitu :

1. Membantu masyarakat khususnya wisatawan yang ingin mengenali dan belajar tentang bentuk dan jenis benda bersejarah beserta filosofinya.

2. Dapat dijadikan sebagai alat pembelajaran bagi siswa dalam proses pengajaran mata pelajaran seni rupa dan budaya. 
3. Dapat memudahkan dalam mengenal kembali dan melestarikan warisan budaya yang sudah hampir hilang.

\section{DAFTAR PUSTAKA}

[1] Yostab, M , Padma C, "Augmented Reality Book Pengenalan Perangkat Gamelan Bali” Kumpulan Artikel Mahasiswa Pendidikan Teknik Informatika (KARMAPATI) Volume 2, Nomor 5, Juli 2013

[2] Rifa'i M , Listyorini1, Latubessy A“ Penerapan Teknologi Augmented Reality Pada Aplikasi Katalog Rumah Berbasis Android ” Prosiding SNATIF Ke-1 2014.

[3] Bowo A. D., 2013 Hariadi Mochammad, Mardi Supeno. 2011, Simulasi Perilaku Pergerakan Objek 3D Media Augmented Reality Berbasis Logika FUZZY, Diakses tanggal 3 Maret 2013

[4] Aditya R, Eko S, Irma P, Bimo S "Implementasi Augmented Reality Di Museum: Studi Awal Perancangan Aplikasi Edukasi Untuk Pengunjung Museum" CITEE 2014 